\title{
AN ORBITAL DERMOID (LINED BY SKIN AND MODIFIED CONJUNCTIVA)
}

\author{
BY \\ P. MCG. Moffatt \\ LONDON
}

A youTH, aged 19 years, attended the Out-patient department of the West London Hospital complaining of a swelling at the upper and outer angle of the left orbit. The swelling had been present for as long as he could remember, but recently he thought it was getting bigger and ached at times; he therefore asked to have it removed.

On examination there was a swelling about the size of a cherry beneath the soft tissues of the outer end of the left eyebrow, and a little below it. It was not tender but pressure caused some discomfort. There was no attachment to the overlying skin and the deep attachments were difficult to gauge, but.it seemed to move fairly freely. The lump fluctuated but was not translucent. Dermoid cyst of the orbit was diagnosed.

Removal of the cyst was performed at the Royal Westminster Ophthalmic Hospital, under local anaesthesia. A small incision was made parallel with the eyebrow over the most prominent part of the swelling and the cyst, which was of a yellowish colour, was found beneath the orbicularis muscle. As the dissection proceeded, it was seen to extend backwards under the orbital margin and assume an hourglass shape. A moderate constriction connected the superficial portion with a much deeper part which, at the time, made one wonder whether the latter were part of the lacrymal gland. The swelling however was easily liberated and finally removed intact by cutting a thin strand of tissue attached to the deep extremity.

The wound healed well but there was an extensive subconjunctival ecchymosis covering about the outer half of the globe which cleared up in three weeks.

The excised specimen was sent to the Pathological Department for examination and report.

\section{Pathological Report by Eugene Wolff}

The cyst is generally ovoid in shape some $17 \mathrm{~mm}$. by $8 \mathrm{~mm}$., tapering, however, towards its upper extremity.

There is a definite constriction which marks the cyst into an upper smaller and a lower larger portion, joined, however, by a wide channel. 


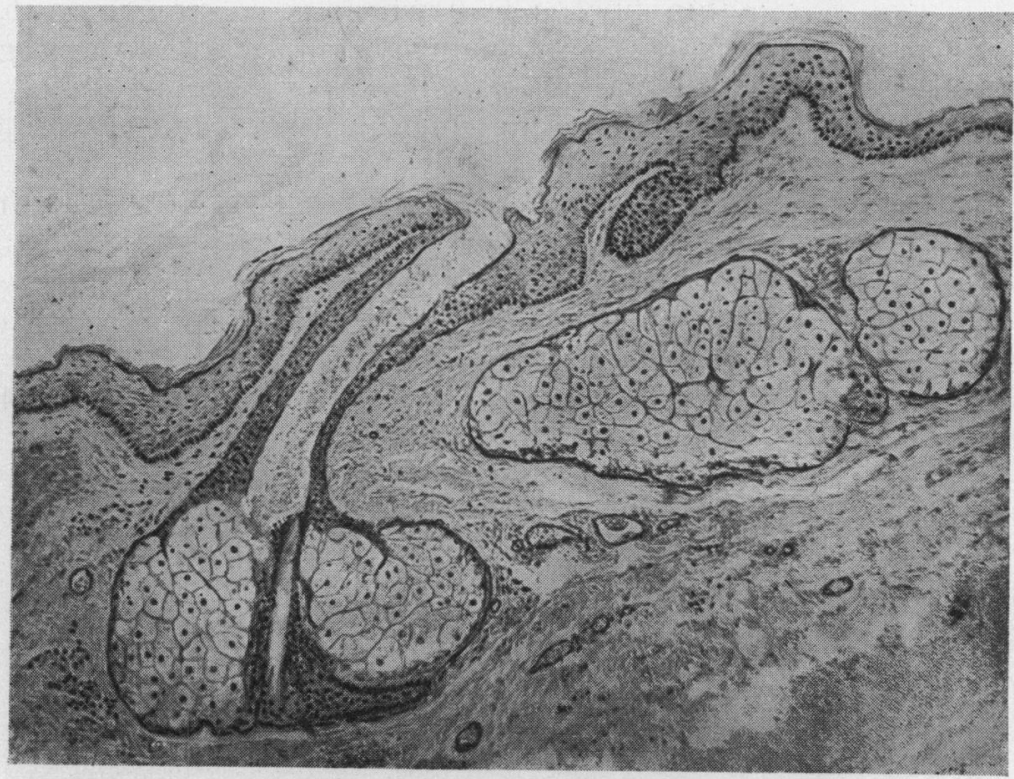

FiG. 1.

A portion of the cyst wall, showing skin and skin structures.

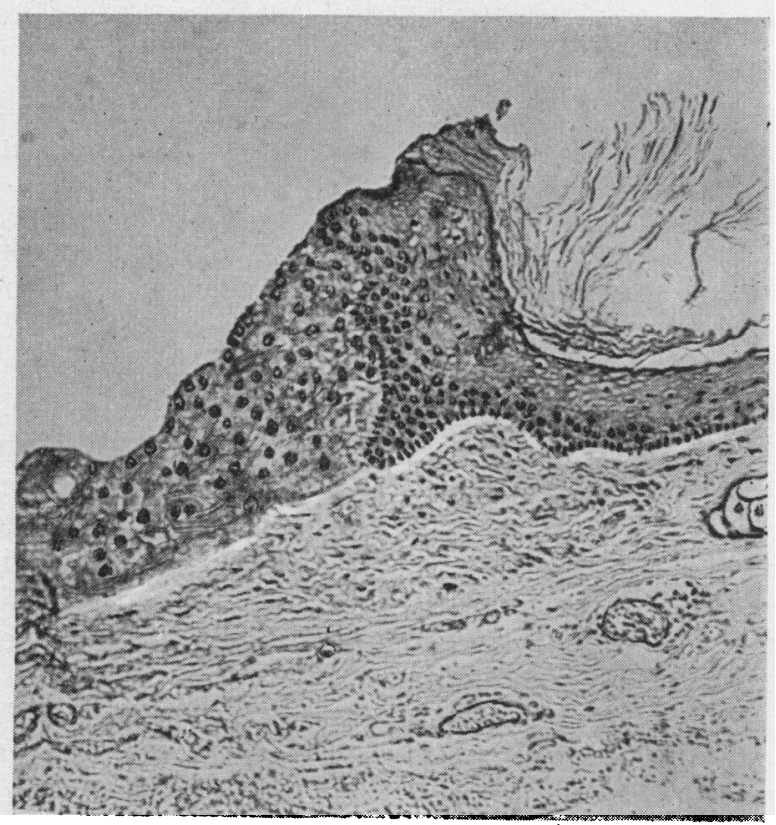

을.

.

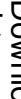

ํํำ

จำ

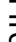

윽

כ

훙

흥

官

$$
\text { ํㅗㅇ }
$$$$
\text { 옹 }
$$$$
\text { 옥 }
$$$$
\frac{7}{2}
$$$$
\text { 궁 }
$$ 
The cyst has a thin fibrous wall which is continuous with a polypoid projection some $3 \mathrm{~mm}$. long into the cavity of the larger portion.

The cyst is lined by epithelium which in parts is like epidermis, in parts like modified conjunctiva.

The epidermal portion shows definite papillary structure (Fig. 1) with hair follicles, sebaceous glands and fewer sweat glands. Keratinisation is well marked.

The junction between the two portions is close to the narrowest portion of constriction and is shown in Fig. 2.

It will be noted that the transition is fairly sharp. On the right, the well-marked skin structure with the epithelium having a definite Malpighian layer, prickle cells and an orderly arrangement

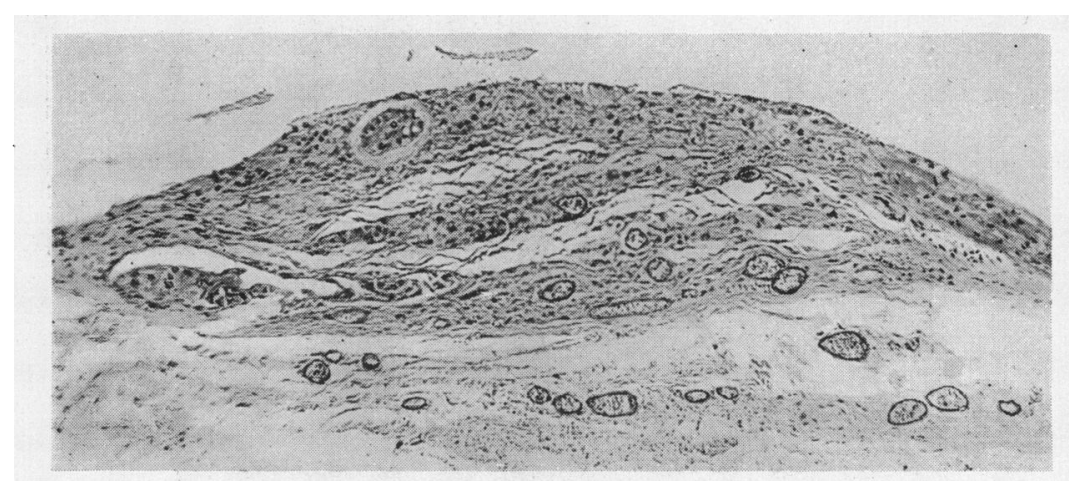

Fig. 3.

A portion of the lining of the cyst converted into granulation tissue containing giant cells.

of the cells which become flatter towards the interior of the cyst and eventually show well-marked keratinisation. To the left the modified conjunctiva shows quite a different disposition of the nuclei, a goblet cell and no keratinisation.

In certain areas of the conjunctival portion the epithelial lining has become much modified. In some places the epithelium is much thinned, in others entirely exfoliated. Here and there the epithelium has been converted into granulation tissue containing giant cells. This is no doubt due to the irritation by hairs, which being shed into the cyst cavity penetrate the conjunctival lining.

The contents of the cyst were a porridge-like, sebaceous mass containing hairs and desquamated cells.

As it has been stated (Bland Sutton: Tumours, 1917) that the skin of orbital dermoids is sensitive and possesses tactile sensibility, a search was made for nerve fibres. None was found; but as no special stain was used this does not exclude their presence. 